\title{
Evaluating a possible role for PKG1 $\alpha$ redox state in chronic hypoxia-induced pulmonary hypertension
}

\author{
Olena Rudyk ${ }^{1 *}$, Oleksandra Prysyazhna', Lan Zhao², Philip Eaton ${ }^{1}$ \\ From 7th International Conference on cGMP Generators, Effectors and Therapeutic Implications \\ Trier, Germany. 19-21 June 2015
}

\begin{abstract}
Background
Hypoxic pulmonary vasoconstriction is a physiological response enabling efficient oxygen delivery to tissues during transient regional lung hypoxia. However, when larger territories are involved, this adaptive mechanism can be detrimental and chronically lead to maladaptation. Such maladaptive events occur commonly due to high altitude hypoxia or pathologies that cause widespread, chronic pulmonary vasoconstriction resulting in hypoxic pulmonary arterial hypertension (HPAH), maladaptive pulmonary vascular remodelling and right heart failure. Previous work from our lab has shown protein kinase G (PKG) $1 \alpha$ is susceptible to oxidation, forming a disulfide dimer which directly activates the kinase resulting in vasodilation and blood pressure lowering. During hypoxia, pulmonary cells become pro-reducing. In this study we tested the hypothesis that this may alter the levels of oxidant-activated PKG1 $\alpha$ and contribute to HPAH pathogenesis.
\end{abstract}

\section{Methods}

A "redox-dead" Cys42Ser PKGI $\alpha$ knock-in (KI) mouse which cannot be oxidant-activated was employed. $\mathrm{HPAH}$ was induced by exposing mice to $10 \% \mathrm{O}_{2}$ for 4 weeks. Cardiac function and pulmonary arterial stiffness was assessed by echocardiography (VEVO 770, Visual Sonics). Right ventricular pressure was measured using a $1.2 \mathrm{~F}$ pressure catheter (Scisence Inc). Vascular reactivity was assessed using a tension myograph (DMT). Tissues for molecular analysis were harvested

\footnotetext{
* Correspondence: olena.rudyk@kcl.ac.uk

'BHF Centre of Research Excellence, King's College London, London, SE1 7EH, UK

Full list of author information is available at the end of the article
}

under hypoxic $\left(10 \% \mathrm{O}_{2}\right)$ or normoxic conditions (room air) respectively to reflect their treatment conditions.

\section{Results}

Acute in vitro hypoxia $(60 \mathrm{~min})$ resulted in a reduction of PKG1 $\alpha$ disulfide level in pulmonary artery (Fig. 1a). A similar decrease in PKG1 $\alpha$ disulfide levels was observed in the lung tissue from mice exposed to acute hypoxia $\left(5-20 \mathrm{~min}\right.$ at $\left.10 \% \mathrm{O}_{2}\right)$. In contrast, $\mathrm{HPAH}$ induced by chronic in vivo hypoxia resulted in significant increase of PKG1 $\alpha$ disulfide in the lung tissue of WT mice, while the level of PKG1 $\alpha$ disulfide in the right ventricle remained similar (Fig 1b-c). There was a trend towards an increase in total PKG1 $\alpha$ expression in the lung and right ventricle. After exposure to chronic hypoxia all mice developed $\mathrm{HPAH}$, mild left ventricular dysfunction and mild body weight loss. However, the KI mice developed a more severe HPAH phenotype, i.e. potentiated right ventricular hypertrophy, higher right ventricular systolic pressure and pulmonary arterial stiffness, compared to WT littermates (Fig. 1d-f). Despite these differential changes, both genotypes had similar compensatory increases in haematocrit and blood haemoglobin levels. Total lung weight was significantly increased after chronic hypoxia; however there were no differences between WT and KI mice. In addition, there was no pronounced development of lung oedema in either genotype. To provide insight into the potential causative importance of PKG1 $\alpha$ redox state in the control of pulmonary vasotone, we compared responses of WT and KI isolated pulmonary arteries to $\mathrm{H}_{2} \mathrm{O}_{2}$. Under normoxic conditions, KI pulmonary vessels had a small but significant decrease in sensitivity to $\mathrm{H}_{2} \mathrm{O}_{2}$ (i.e. a rightward shifted dose-response) compared to WT; this was despite equal constriction to the pressor agonist 


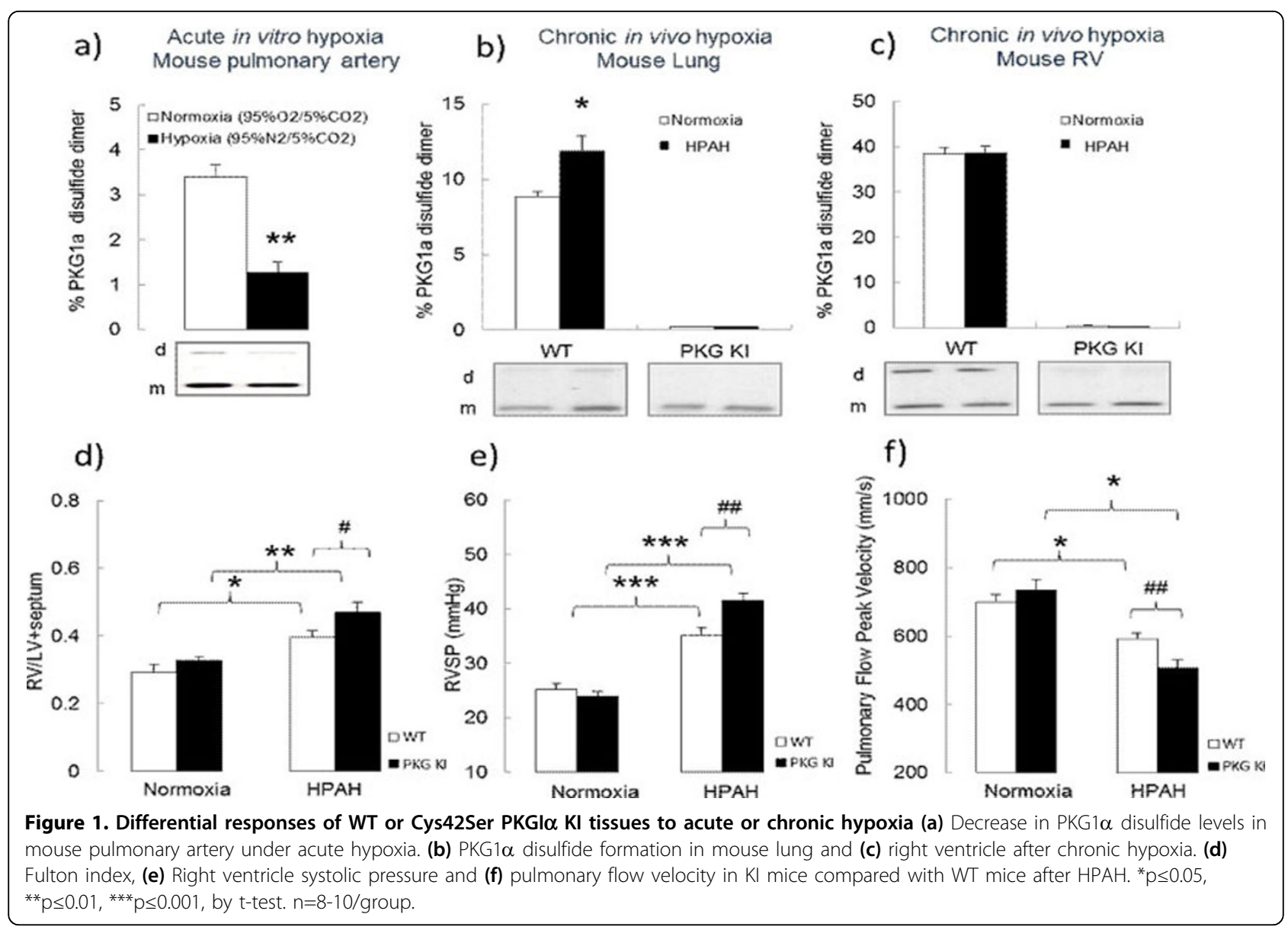

U-46619 in each genotype. Experiments comparing vascular reactivity in WT and KI mice after HPAH employing both tension myograph and mouse isolated lung approaches are in progress.

\section{Conclusion}

We conclude that PKG1 $\alpha$ plays a role in both acute hypoxic vasoconstriction as well as changes during chronic HPAH. We speculate that disulfide PKG1 $\alpha$ levels are lowered, by chemical reduction, during acute hypoxia - potentially contributing to acute hypoxic pulmonary vasoconstriction. In contrast, during chronic hypoxia there is exacerbated PKG1 $\alpha$ oxidation which may be protective by keeping the pulmonary arterial pressure low, and thereby reducing the afterload on the right ventricle in the setting of HPAH. Redox dead PKG1 $\alpha$ KI mice lack this protective mechanism and therefore have exacerbated hypoxia-induced pulmonary hypertension phenotype. Interventions targeting PKG1 $\alpha$ oxidation in the pulmonary vasculature will help to test if this mechanism truly serves to attenuate HPAH progression and consequent right heart failure.

\section{Authors' details}

'BHF Centre of Research Excellence, King's College London, London, SE1 7EH, UK. ${ }^{2}$ Experimental Medicine, Imperial College London, London, SW7 $2 A Z, U K$.

Published: 2 September 2015

doi:10.1186/2050-6511-16-S1-A80

Cite this article as: Rudyk et al:: Evaluating a possible role for PKG1 $\alpha$ redox state in chronic hypoxia-induced pulmonary hypertension. $B M C$ Pharmacology and Toxicology 2015 16(Suppl 1):A80.

Submit your next manuscript to BioMed Central and take full advantage of:

- Convenient online submission

- Thorough peer review

- No space constraints or color figure charges

- Immediate publication on acceptance

- Inclusion in PubMed, CAS, Scopus and Google Scholar

- Research which is freely available for redistribution 